\title{
Correction to: The Palgrave Handbook of Digital Russia Studies
}

\author{
Daria Gritsenko, Mariëlle Wijermars, and Mikhail Kopotev
}

\section{Correction to:}

D. Gritsenko et al. (eds.), The Palgrave Handbook of Digital Russia Studies, https://doi.org/10.1007/978-3-030-42855-6

This book was inadvertently published with an incorrect affiliation for the Authors Ekaterina Artemova, Anastasia Bonch-Osmolovskaya, Frank Fischer, Arto Mustajoki, Polina Kolozaridi and Daniil Skorinkin. The affiliations have now been amended in the book.

The correct affiliation is

Higher School of Economics

(HSE University)

Moscow, Russia

The updated original online version for this book can be found at https://doi.org/10.1007/978-3-030-42855-6

(C) The Author(s) 2021 